\title{
Design of Constant Pressure Water Supply System based on Profibus Field Bus
}

\author{
Y.C. CHEN \& W.G. LI \& Q.L. YANG \& L.L. HUANG \\ Faculty of Mechanical \& Electrical Engineering, Kunming University of Science \& Technology, Jingming \\ South Road, Kunming, Yunan, 650504, P.R. China
}

\begin{abstract}
This paper presents the design of constant pressure water supply system based on PROFIBUSDP field bus, the design include the construction of control network of host computer monitoring system, and the construction of bottom control system. The proposed design approach explains the composition of control network in detail, the configuration of master station and slave station applying STEP7. The master station adopts S7-300, the slave station adopts S7-200, and in order to implement the field monitoring, the "PC+Network card +WinCC" is used as the second class master station, and the monitoring main interface is designed applying WinCC6.0 soft.
\end{abstract}

KEYWORD: PROFIBUS-DP; STEP7; WinCC; Constant pressure; Water supply

\section{INTRODUCTION}

Constant pressure water supply is a symbol that improving the human living standard applying science and technology, and is a milestone in the history of human civilization. Constant pressure water supply not only improves the quality of the water supply, but also saves a lot of energy and manpower material resources, and has very high social and economic benefits. The application of field bus technology to the whole water management and control system will greatly improve the quality and the management of water supply [1].

With the rapid development of economy and urbanization in China, people have much higher requirement to water quality and stability whether in household water consumption or industrial factory, keeping the pressure constant of the water is a very important problem. In the traditional designs such as constant speed pump water supply, high tower water supply, air pressure tank water supply, all of these designs have the problems like less water pressure, low efficiency, or electricity resources waste more or less.

This design is mainly designed for residential areas, and the design of the constant pressure water supply system is based on the field bus technology, which is divided into two parts: the first part is the design of control system and equipment selection; the second part is the configuration of control system network, this paper mainly introduces the design of the second part [2].

\section{PROCESS FLOW OF WATER SUPPLY SYSTEM}

This water supply system is mainly designed for residential areas, and the design of this system is mainly based on the processing technology of the Kunming fifth water plant, the process flow chart of water supply system is shown in Figure.1.

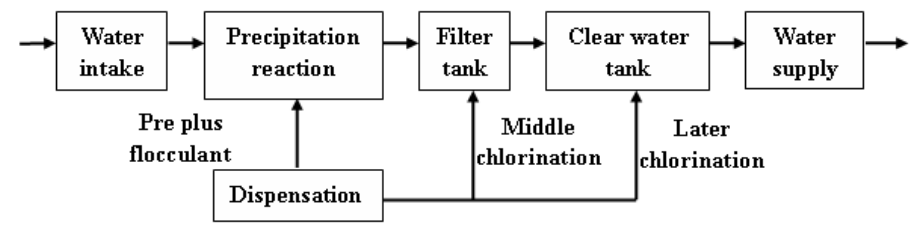

Figure 1 Process flow chart of water supply system

\section{COMPOSITION OF CONTROL NETWORK OF WATER SUPPLY SYSTEM}

This system is constructed based on Profibus-DP field bus, the network configuration diagram is shown in Figure 2. The substation is controlled by S7-200, the distributed control structure can improve the system reliability and stability. In order to realize the network configuration, the information exchange and integration control, we use a high performance PLC (S7-300) as the main station. At the same time, in order to implement the field monitoring, we use the ordinary "PC+Network card $+\mathrm{WinCC}$ " as the second class master [3][4]. 


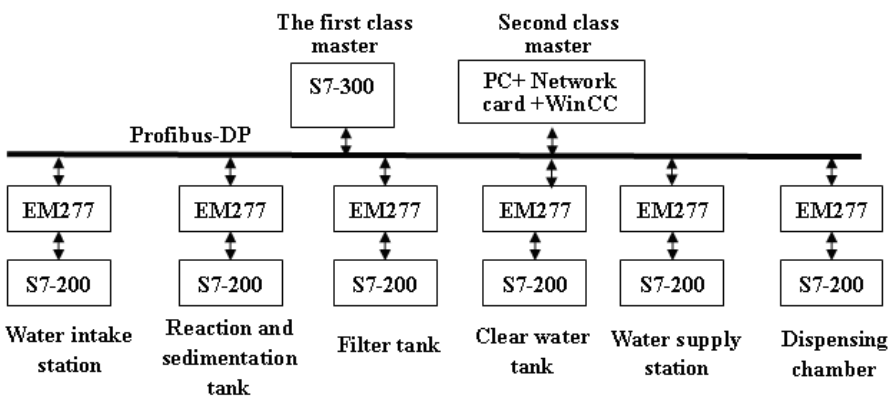

Figure 2 The network configuration diagram

\section{COMMUNICATION OF PROFIBUS-DP}

Communication of PROFIBUS-DP is realized by the token passing mode between the master stations, and the master-slave mode between the slave stations. The token is in fact a special message; it can only be passed between the master stations. According to the ascending order of the master station address, the token rings in each master station are orderly transferred.

While a master station gets the token message, the master can implement the master work within a certain period, in this period, it can communicate with all slave stations in accordance with the masterslave communication relation table, and can also communicate with the master station in accordance with the main-main communication relationship. Token passing procedure ensures that each station in a specified period can get the exact bus access right (token).

The communication between DP master station and DP slave station follows the master-slave principle, DP master station accesses DP slave station sequentially by polling list, master station and slave station exchanges the user data periodically. A message cycle between DP master station and DP slave station is made up of request frame sent by DP master station and response farm returned by DP slave station. Any master can read input/output image of DP slave station, but only a specified DP master station can be allowed to write data to DP slave station.

\section{THE DETAILED APROACH OF CONFIGURATION APPLYING STEP7}

STEP7 is a powerful programming and configuration tool, the main program is SIMATIC Manager, each function module can be called from main program to carry on the hardware configuration, network configuration, program design, network diagnosis and PLC simulation.

\subsection{Configuration of master station S7-300}

The steps of configuration for master station S7-300 is as follows [3]:

Firstly, open the SIMATIC Manager, create a new project, the project is named as "constant pressure water supply". Select the project name "constant pressure water supply project" in the left navigation bar, and insert the "SIMATIC 300 Station" from the shortcut menu, rename the "SIMATIC 300 Station" as the master station, then select the master, and enter into hardware configuration of host computer.

Secondly, select a rack rail for the master station, add a piece of power supply (PS 307 2A), add a piece of CPU (315-2 DP), the order number choose "6ES7 315-2AF03-0AB0", the version choose "V1.2", and the information description of CPU can be obtained in the lower right corner. The DP port address is set to 2 on "CPU attribute" from the popup menu.

Thirdly, click the "next" properties button, the transmission rate choose " $1.5 \mathrm{Mbps}$ " in the network settings tab, the DP type choose the "PROFIBUS", and then click "OK", the master station has established a PROFIBUS-DP connection, by default for DP master, this station hardware configuration has been completed.

\subsection{Configuration of slave station S7-200}

For the constant pressure water supply system, we use S7-200 PLC to control each link, but the S7-200 PLC has no DP interface that used to connect with the PROFIBUS-DP bus, and to realize the communication with S7-300 PLC, it is necessary that the external communication processing module EM277 is used [4].

EM277 belongs to non-intelligent module (without CPU, and can not download program), we can not set its address by downloading configuration information, and need to apply the hardware to set its address, which is shown in Figure.3, in the upper left corner of the EM277, two switches are used to set the address.

DP master station can not directly access the I/O of intelligent DP slave station, but can access the communication area in I/O address space of CPU. CPU of intelligent slave station is used to process data exchange between the address area and the actual I/O data. While configuration, the specified $\mathrm{I} / \mathrm{O}$ area that used for data exchange between master station and slave station can not occupy the physical address areas of $\mathrm{I} / \mathrm{O}$ module.

The data exchange between master station and slave station is done automatically by the operating system of PLC periodically; do not need the user programming, but the user need to configurate the intelligent communication connection and data exchange between master station and slave station. 
This kind of communication mode is known as master-slave mod. After configuration each slave stations according to above method, we can get the network configuration diagram, which is shown in Figure.3. Table.1 lists the corresponding communication area address for DP master station and slave station network.

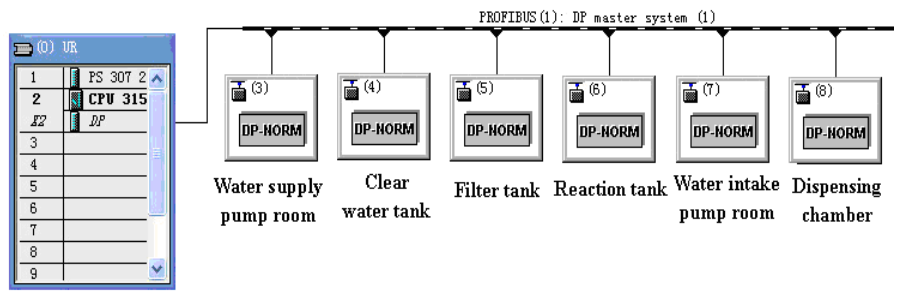

Figure 3 Network configuration diagram obtained by STEP7

Table 1 Communication address area

\begin{tabular}{|c|c|c|c|c|}
\hline Station name & Station location & $\mathrm{I} / \mathrm{O}$ size & $\begin{array}{c}\text { Communication area in } \\
\text { master }\end{array}$ & $\begin{array}{c}\text { Communication area in } \\
\text { slave }\end{array}$ \\
\hline \multirow{2}{*}{ Water supply Pump room } & \multirow{2}{*}{3} & \multirow{2}{*}{32 word out/32word in } & IB300 IB363 & VB564 VB627 \\
\hline & & & QB300 QB363 & VB500 VB563 \\
\hline \multirow{2}{*}{ Clear water tank } & \multirow{2}{*}{4} & \multirow{2}{*}{ 4word out/4word in } & IB400 IB407 & VB508 VB515 \\
\hline & & & QB400 QB407 & VB500 VB507 \\
\hline \multirow{2}{*}{ Filter tank } & \multirow{2}{*}{5} & \multirow{2}{*}{ 4word out/16word in } & IB450 IB481 & VB508 VB539 \\
\hline & & & QB450 QB457 & VB500 VB507 \\
\hline \multirow{2}{*}{ Reaction tank } & \multirow{2}{*}{6} & \multirow{2}{*}{ 4word out/16word in } & IB500 IB531 & VB508 VB539 \\
\hline & & & QB500 QB507 & VB500 VB507 \\
\hline \multirow{2}{*}{ Water intake pump room } & \multirow{2}{*}{7} & \multirow{2}{*}{8 word out/32word in } & IB550 IB613 & VB516 VB579 \\
\hline & & & QB550 QB565 & VB500 VB515 \\
\hline \multirow{2}{*}{ Dispense champer } & \multirow[b]{2}{*}{8} & \multirow{2}{*}{8 word out/32word in } & IB650 IB713 & VB516 VB579 \\
\hline & & & QB650 QB665 & VB500 VB515 \\
\hline
\end{tabular}

\section{DESIGN OF MONITORING INTERFACE}

In order to monitor the field more effectively, we use the physical similarity graphs to simulate the field device, and use pictures with different colors and states to denote the state of the equipment, the button and the data display panel are used to control device and to display the device parameters. This design includes one main interface and six sub-interfaces for the system. The structure of interface is shown in Figure 4.

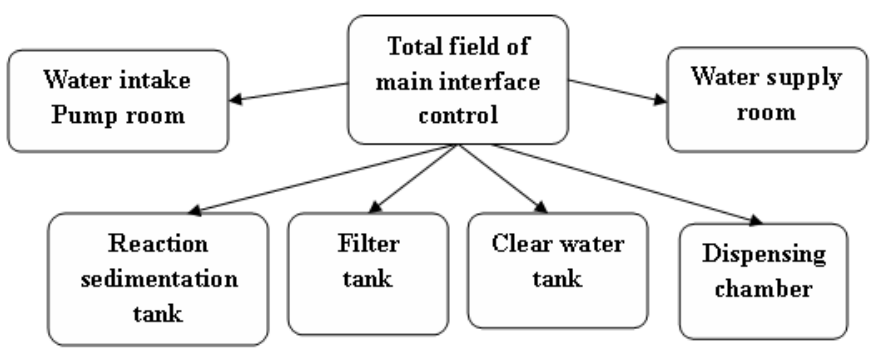

Figure 4 Structure diagram of the monitoring interface

Clicks the corresponding site from main interface, we can enter the corresponding sub-interface, and the links for each site can be switched each other. Figure. 5 shows the main interface of the constant pressure water supply system, which is drawn by WinCC6.0 soft.

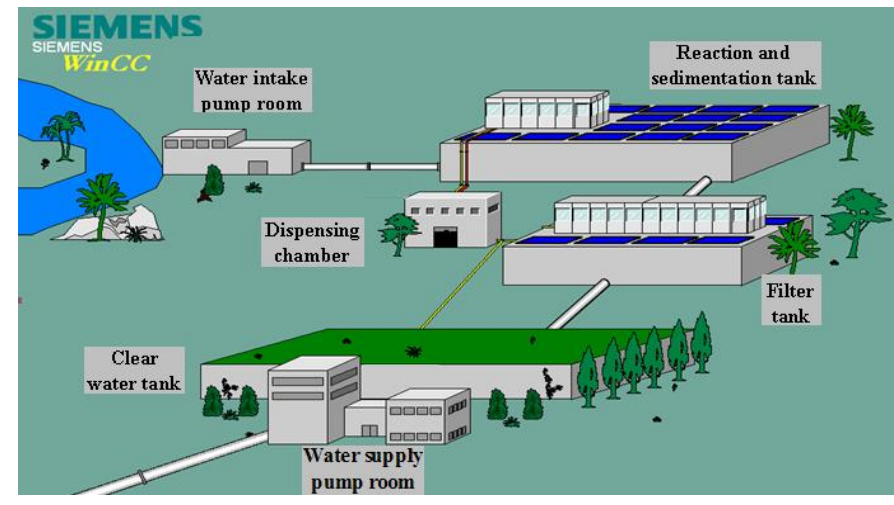

Figure 5 The monitoring main interface of constant pressure water supply system

\section{CONCLUSIONS}

This paper ultimately achieves the design of the constant pressure water supply system for the residential areas applying PROFIBUS-DP field bus network. The entire field control system is constituted as follows: S7-200 PLC is used as the underlying control equipment, and S7-300 PLC is 
used as the system control station and "PC+ Network card + configuration software" is used as monitoring machine.

Whole communication network is established by applying high performance PROFIBUS-DP field bus, which can realize communication and control of the bottom slave station. The communication mode adopts the master-slave relationship, configurations of the network for all sites are achieved in STEP7, the addresses and communication variable areas are allocated for all sites, and communication processing program is compiled. The CP5611 network card is inserted into the monitoring host PC, PROFIBUS communication network has been switched in. The proposed Field bus control system can also use a WinCC server to access Internet/Intranet; enterprise management personnel can access the site data through the Internet/Intranet, so that managers can make more rational and more efficient decision [5].

\section{REFERENCES}

[1] Gan, Y.M. 2004. The Field bus Technology and Its Application. Beijing: China Machine PRESS.

[2] Zou, Y.R. 2003. The design and development of the field bus control system. Beijing. China National Defense Industry Press, 2003

[3] Liao, C.C. 2005. S7-300/400 PLC Application Technology. Beijing: China Machine PRESS.

[4] Wen, Z.F. 2002. Tutorial of simatic S7-200 Programmable controller. Beijing: Beijing institute of technology press.

[5] Gao, Q.H. 2004. Application of PLC technology and design examples. Beijing: China Posts and Telecom Press. 